\title{
Sperm selection techniques and antioxidant fortification in low grade semen of bulls: Review
}

\author{
Thakur Krishna Shankar Rao, Niranjan Kumar, Navinkumar B. Patel, Indrasen Chauhan ${ }^{1}$ and Shailendra Chaurasia \\ Department of Livestock Production and Management \\ College of veterinary Science and Animal Husbandry, Navsari Agricultural University, Navsari, Gujarat, India; \\ 1. National Academy of Agricultural Research Management, Rajendranagar, Hyderabad, Andhra Pradesh, India \\ Corresponding author: Thakur Krishna Shankar Rao, email: tksrao.vet@gmail.com \\ Received: 27-12-2012, Revised: 30-01-2013, Accepted: 31-01-2013, Published online: 14-06-2013
}

\begin{abstract}
How to cite this article:
Rao TKS, Kumar N, Patel NB, Chauhan I and Chaurasia S (2013) Sperm selection techniques and antioxidant fortification in low grade semen of bulls: Review, Vet World 6(8): 579-585, doi: 10.5455/vetworld.2013.579-585
\end{abstract}

\begin{abstract}
The low grade ejaculates are very common in bulls. Low grade ejaculates might be due to age or non specific factors like thermal stress, transport and vaccination stress during the dynamic life of bulls. Lipid peroxidation of membrane induced sperm damage further aggravates the situation. Researches reveal that selection of sperm and antioxidant fortification play crucial role in improving the quality of semen. Different methods used for semen up-gradation like washing, sedimentation, swim up procedure and filtration like percoll gradient, glass wool, sephadex and sephadex ion exchanger with significant improvement in motility, Hypo osmotic swelling test reactivity, viability and acrosomal integrity. Antioxidants are added directly to extender at standard dose rate with positive result. Among different filtration column used sephadex ion exchanger (FS+IE) was superior over other in improving the semen quality especially when fortified with Vitamin E. Moreover a complete protocol is required, which contain both antioxidant fortification and sperm selection simultaneously to handle the low grade semen from sub-fertile bulls.
\end{abstract}

Keywords: antioxidant, bull, genetic, semen, sperm

\section{Introduction}

The improvement in quality of semen is an important aspect for maximum utilization of genetically superior sub-fertile sire, for the reason of age and or non specific factors like thermal stress, transport and vaccination stress during their dynamic life show a low grade semen quality than previously. It is usual practice to feed poor quality ration, especially silage, in scarcity period to the bulls which shown an increase in abnormal and dead spermatozoa count in semen due to some unknown factors [1]. The metabolic byproducts released by infertile spermatozoa are believed to adversely affect the fertilization potential of fertile male gamete, ultimately influences the fertility of productive bull. Peroxides, free radicals, various proteolytic enzymes released from disintegrating spermatozoa damage the plasma membrane of fertile spermatozoa [2]. More than 75 percent of total ejaculates are discarded due to poor initial motility even in high quality elite cross bred bulls [3]. The problems of low grade semen ejaculates are common predominantly in crossbred bulls. Ejaculates of semen from bulls with compen-sable sperm defects seem to be significantly improved by filtration of neat or extended semen. Filtration significantly improves fertility of sub-fertile bulls after removal of dead and abnormal spermatozoa from extended ejaculates using different filtration media.

This article is an open access article licensed under the terms of the Creative Commons Attribution License (http://creativecommons. org/licenses/by/2.0) which permits unrestricted use, distribution and reproduction in any medium, provided the work is properly cited.
Previously different methods were tried for improving the low grade semen by reducing the number of dead or abnormal cells by trapping it in filtration column. Fertile and quality spermatozoa can be selected using different processes, such as centrifugation, washing, pooling, chromatography, sedimentation (bovine serum albumin gradient), percoll gradient, and swim up procedure, followed by glass wool, glass bead, sephadex gel and sephadex with ion-exchanger column filtration [4]. Sephadex with ion exchanger significantly improve the quality of fresh semen [5], especially when fortified with anti-oxidant agent like vitamin E [6]. The sephadex and ion exchanger filters are superior over other as it filters the extended semen efficiently. These techniques not only allow for selection of best sperm which enhances motility but may also be used to remove the extender and dead cells present in frozen thawed sperm sample.

The success of semen preservation depends largely on resistance of spermatozoa to ultra low temperature. However, conventional technique i.e. freezing protocol without antioxidant fortification, are able to recover only small portion of the frozen germplasm on thawing. Rest being destroyed or become less viable moreover more viability is desired to achieve target conception and fertility. The reduction or loss in viability and fertility can be attributed to many changes takes place in the sperm cells during cryopreservation. Changes in sperm cell structure and function related to cold shock have often been reported, especially in plasma membrane, acrosome and mitochondria. Plasma membrane and acrosome are important sites of the 


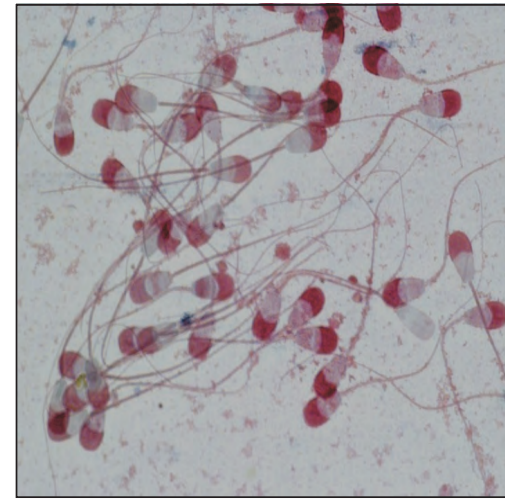

Figure-1. Spermatozoa showing Intact and reacted acrosome.

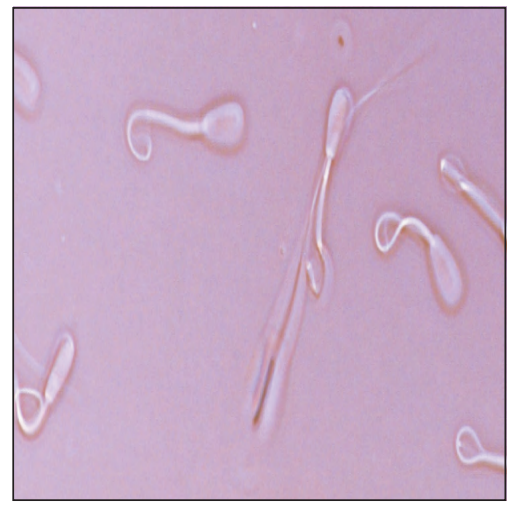

Figure-2. HOST positive and negative spermatozoa

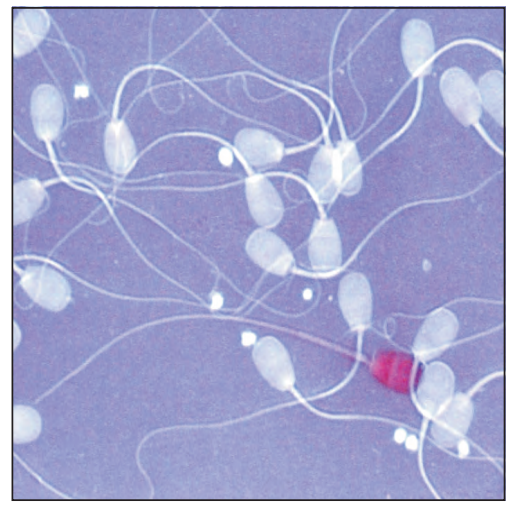

Figure-3. Live (non eosinophilic) and dead (eosinophilic) spermatozoa changes caused by cryopreservation process. Cryopreservation affects the lipid architecture of plasma membrane [7] and metabolism due to high amount of polyunsaturated fatty acid with significantly less cytoplasmic component containing antioxidant [8]. It is susceptible to peroxide damage with subsequent loss of membrane integrity, impaired cell function and decreased motility of spermatozoa. Cold shock enhances susceptibility of spermatozoa to lipid peroxidation and structure alteration [9]. Lipid peroxidation of membrane is considered to be the key of reactive oxygen species (ROS) induced sperm damage [10], leads to infertility. Moreover, buffalo bull sperma-tozoa are more vulnerable to oxidative damage as compared to cattle bull spermatozoa [7,11]. Addition of antioxidant might be helpful in preventing the damage under such condition especially ascorbic acid and á-tocopherol [10]. It is therefore, worthwhile to fortify the low grade semen especially after filtration for improving the keeping quality of semen.

\section{Purpose}

Maximizing the production of high grade semen i.e., without discarding too many poor qualities semen ejaculates.

\section{Principle}

Isolation and selection of motile from immotile sperm cells by means of different process including filtration column, as it provides barrier to trap the inactive male gamete, followed by antioxidant fortification to preserve intact membrane and reduce oxidative stress to spermatozoa.

Ideal protocol for selection of quality sperm with high fertilizing ability should be, nontoxic to spermatozoa, easy to perform and cost effective, efficient and high speed of processing and capable of selecting best sperm population.

\section{Evaluation of semen}

Semen is evaluated in terms of spermatozoa concentration, individual motility, membrane integrity using Hypo osmotic swelling test (HOST), live-dead percentage, In vitro fertilization, acrosomal intactness, sperm abnormalities etc. (Fig-1, 2 and 3). The semen profiles were studied before and after processing (different process including filtration and antioxidant fortification) to access the effect of the same.

\section{Different methods of semen upgradation}

1. Washing Procedure: The semen sample was centrifuged $\left(800 \mathrm{x}\right.$ g for 10 minutes at $\left.16^{\circ} \mathrm{C}\right)$ in a test tube followed by removal of seminal plasma using a Pasteur pipette. Tris-citric acid was then added to semen up to previous volume, and then pellets were dispersed in tris buffer. The second centrifugation was done in analogous condition and supernatant was removed and reconstituted to the original volume by buffer [12]. Washing of semen is almost similar to sephadex filtration with respect to post-thaw recovery rate.

2. Sperm sedimentation: Semen sample was taken in special glass tube with inner cone that allow only those spermatozoa capable of swimming out from the liquidized semen to the sediment in the inner cone. Here ROS production minimized because centrifugation not required here. Recovery rate is very less in this method.

3. Swim-up procedure: The technique is performed in a capped plastic tube $(12 \times 55 \mathrm{~mm})$ in presence of HEPES and $\mathrm{CO}_{2}$. The one volume of semen sample layered under 10 volume of Tyrode's medium (TALP) and incubated at $37^{\circ} \mathrm{C}$ for $1 \mathrm{hrs}$ in the presence of $5 \%$ $\mathrm{CO}_{2}$ in $\mathrm{CO}_{2}$ incubator. Following incubation, $1.5 \mathrm{ml}$ of supernatant is harvested in sterile container. Mustafa et al., [13] documented 33\% recovery rate of motile spermatozoa in swim up procedure while it was around $95 \%$ in filtration.

4. Glass wool column filtration procedure: Disposable Pasteur pipette of $12 \mathrm{~cm}$ length with an inner diameter of $0.75 \mathrm{~cm}$ packed with $40-50 \mathrm{mg}$ of borosilicate glass wool, micro fiber is gently placed at a depth of $2 \mathrm{~cm}$. The column was vertically suspended and rinsed repeatedly with different media including $5 \mathrm{mM}$ caffeine sodium benzoate and $10 \mathrm{ì} / \mathrm{mL}$ heparin to remove any loose wool fiber prior to filtration. The rinsed column was inserted in collection tube at $37^{\circ} \mathrm{C}$ [14-16]. The filtration process which takes about 3 


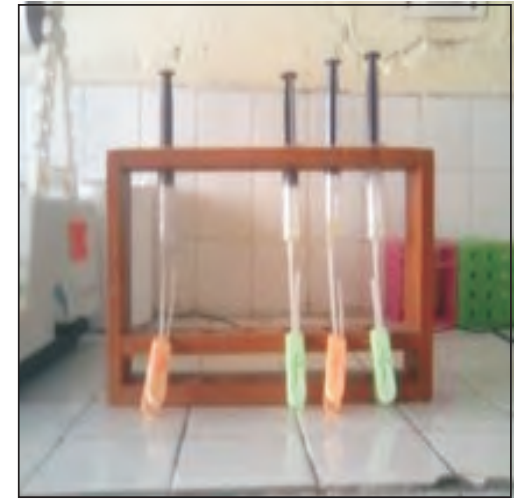

Figure-4. Filtration of semen using Control vs FS, FS+IE, FS+IE+ Vit E

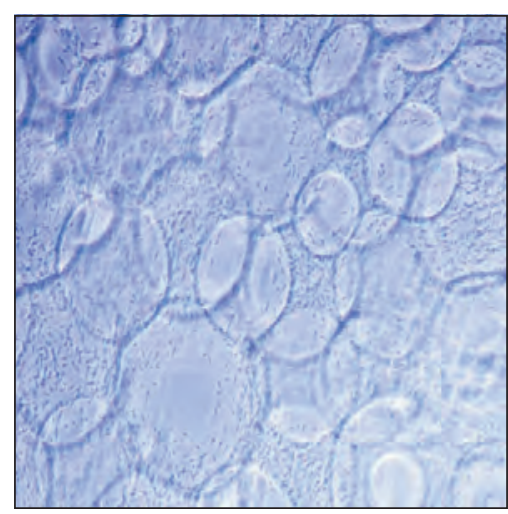

Figure-5. Microscopic view of trapped spermatozoa in Sephadex filter

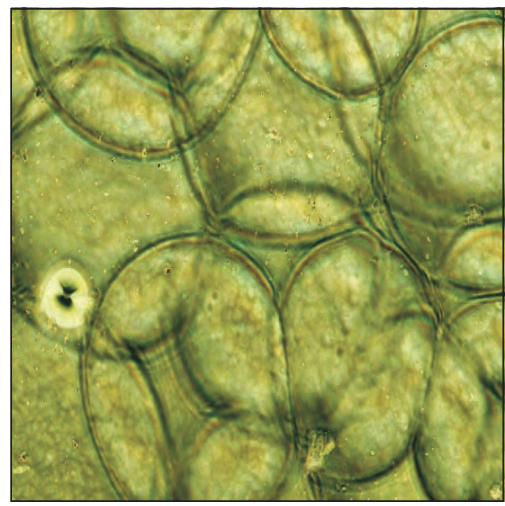

Figure-6. Microscopic view of blank sephadex filter minutes was carried out at room temperature protected from bright light and draught. Glass wool filtration is rapid and very efficient technique to obtain a high percentage of functional sperm [17]. Glass beads can be used to improve substandard semen ejaculates [18]. Glass wool filtered semen was better as compared to sephadex and percoll gradient especially for embryo production [16]. However the effect was not significant in buffalo semen [19].

After filtration, the glass wool should be gently removed from the Pasteur pipette and rinsed with trisbuffer in watch glass. Smear prepared from this solution may used for calculating the percentage of dead and abnormal spermatozoa.

Glass wool filtration of semen has beneficial effect as it showed improved motility of spermatozoa and lower incidence of abnormal spermatozoa. Spermatozoal concentration declined because of effective retention of dead and abnormal sperm cells, especially the spermatozoa with mid-piece and tail abnormality. Capacity to withstand cold shock and freezability reported to improved after the filtration. All beneficial effects were more pronounced in poor quality/low grade semen, as compared to high grade semen.

5. Percoll separation procedure: Percoll solution stock was constituted in 9:1 ratio containing mixture of percoll and a $10 \mathrm{x}$ stock of salt solution $[2.889 \mathrm{~g} \mathrm{NaCl}$, $0.238 \mathrm{~g} \mathrm{KCl}, 0.116 \mathrm{~g} \mathrm{KH}_{2} \mathrm{PO}_{4}, 0.112 \mathrm{~g} \mathrm{CaCl}_{2}$ and 0.163 $\mathrm{g}$ Hepes in $50 \mathrm{ml}$ distilled water]. The $90 \%$ percoll solution was obtained by diluting a stock of percoll solution with Bracket and Oliphant (BO) media. For preparing $45 \%$ percoll solution, 90 percent percoll solution was mixed at a $1: 1$ ratio with medium. In a 15 $\mathrm{ml}$ conical tube, $1.5 \mathrm{ml}$ of the $90 \%$ Percoll solution was added and $1.5 \mathrm{ml}$ of $45 \%$ Percoll was deposited. The average percent motility in percoll was higher as compared to sephadex and glass wool. More over greater development rate to blastocyst stage than cleaved embryo produced by percoll filtration as compared to glass wool [16].

6. Preparation of sephadex (FS) columns: Tris-citric acid buffer $[24 \mathrm{mg} / \mathrm{ml}$ Tris hydroxymethyl amino- methane, $14 \mathrm{mg} / \mathrm{ml}$ citric acid and $8 \mathrm{mg} / \mathrm{ml}$ glucose in distilled water, osmotic pressure $325 \mathrm{mOsm} / \mathrm{kg}$, $\mathrm{pH}$ 7.0] without egg yolk and glycerol was used to prepare 8 percent (w/v) slurries of sephadex. The slurry was allowed to swell overnight at $4^{\circ} \mathrm{C}$. The filtration column was prepared in a $10 \mathrm{ml}$ disposable plastic syringe. A hole $(1.6 \mathrm{~mm})$ was drilled at $8 \mathrm{ml}$ level of the syringe barrel to allow removal of air trapped in the barrel. A small amount of glass wool was compressed with the plunger to bottom of the barrel to prevent the loss of sephadex. A plastic tube was attached to the tip of the syringe and clamped. The free end of the tubing was inserted in the filtrate collection tube. In FS (sephadex filtration) column, $3 \mathrm{ml}$ slurry ( $0.25 \mathrm{~g}$ ) of sephadex was gently layered over the glass wool and allowed to settle for 3-4 minutes (Fig. 4, 5 and 6).

Mechanism of trapping by sephadex: A barrier is provided by sephadex particles or allows immotile or dead spermatozoa to agglomerate. The protein may be present on capacitated spermatozoa which bind with sephadex particles easily.

7. Preparation of Sephadex (FS) plus Ion exchanger (IE) filtration column: In same line as sephadex column, the FS +IE column was prepared. For this 1.25 $\mathrm{ml}(0.1 \mathrm{~g})$ di-ethyl amino-ethane-52 (DEAE positive charge) cellulose was layered over sephadex (0.25 gm) followed by carboxy-methyl-52 (CM-negative charge) cellulose layer $(0.1 \mathrm{~g})$. The slurries of DEAE and CM cellulose prepared fresh before preparation of column [6].

Ion exchanger: An ion exchange resin consists of an insoluble matrix with attached covalently charge group. Both positive and negative charged ion exchangers are available. Negatively charged exchangers binds with positively charged ions and vice versa. Anion binds with one type of cation however when presented with a second type of cation, this may displace or exchange with first one. Hence these resins are called cation- exchange resins.

Mechanism of trapping in Ion exchanger: Surface charge of sperm changes after its death, therefore on the basis of difference in charge between live and dead 
Table-1. Effect of filtration on motility of sperm after freezing [3].

\begin{tabular}{|c|c|c|c|c|}
\hline Stage & $\begin{array}{l}\text { Control } \\
\text { Mean } \pm \text { S.E }\end{array}$ & $\begin{array}{l}\text { FS } \\
\text { Mean } \pm \text { S.E }\end{array}$ & $\begin{array}{l}\text { FS+IE } \\
\text { Mean } \pm \text { S.E }\end{array}$ & $\begin{array}{l}\text { FS+IE+ Vit.E (Vit. E } 1 \mathrm{mg} / \mathrm{ml}) \\
\text { Mean } \pm \text { S.E }\end{array}$ \\
\hline Pre-freez & $50.08^{a} \pm 0.01$ & $60.05^{\mathrm{b}} \pm 0.02$ & $65.60^{c} \pm 0.03$ & $68.46^{c} \pm 0.03$ \\
\hline Post-thaw & $25.97^{\mathrm{a}} \pm 0.01$ & $37.14^{\mathrm{b}} \pm 0.01$ & $41.06^{\mathrm{c}} \pm 0.02$ & $44.49^{d} \pm 0.01$ \\
\hline \%Improvement over control & - & 43.01 & 58.10 & 71.31 \\
\hline
\end{tabular}

* Means bearing different superscript within same row differ significantly $\left({ }^{\mathrm{ab}} P<0.05\right)$. FS: sephadex filtration, IE: Ion Exchanger

spermatozoa can be separated by using respective opposite charges.

Filtration of semen: The semen was filtered at room temperature in prepared column. The syringe was secured vertically in filtration frame. Before filtration of semen the buffer part of slurries was removed by releasing the tubing clamp, covering the hole on the syringe and forcing the plunger manually. The plunger was not allowed to pass through the hole in order to prevent the lifting of the column while removing the plunger. The extended semen sample was gently layered on to the column and filtered at rate of $1.5 \mathrm{ml}$ per minutes. Fortification of antioxidant with semen before filtration improved the recovery rate of spermatozoa through the same sephadex and ion exchange column more than $90 \%$ [6].

Effect of filtration on semen profiles: There was significant improvement in motility, live spermatozoa and intact acrosome after filtration of semen through sephadex G-15 [20], G-100, G-200. The semen volume and sperm concentration decreased after filtration significantly $(P<0.01)$. Considerable decrease in sperm abnormalities was also reported. The G-100 and G-200 column was proved more efficient as compared to G-25 to G-75 [21]. Sephadex filtration was superior over simple washing by centrifugation with respect to different sperm profiles. FS + IE column method was superior over FS and other methods [22,23]. Post-thaw recovery rate of motile spermatozoa was higher in filtered semen as compared to non-filtered (68 vs 39\%) semen. Semen quality was best preserved by filtration of semen in sephadex plus ion exchanger combination method fortified with vitamin E [6]. Tail and total abnormality of spermatozoa was also reduced significantly. The effect of traditional glass wool filtration was improved by using annexin $\mathrm{V}$ binding which isolates apoptotic marker spermatozoa [24] and thus enhances the results of IVF. The column filtration is effective methods to enhance sperm quality by selecting viable and morphologically normal spermatozoa without altering DNA, plasma membrane, mitochondrial sheath integrity or inducing premature acrosome reaction $[25,26]$. However, in vitro fertilizing capacity not differs significantly for buffalo semen [19] after filtration. Selection of sperm based on sperm membrane maturity includes hyaluronic acid (HA) sperm binding, as HA binding site on sperm regarded as sign of sperm maturity [27]. Selection of best sperm based on live sperm organelle morphology examination in inverted light microscope in magnification of over 6000 came into existence. Now-a-days spectro- scopy is also used for selection of sperm for the purpose of in-vitro fertilization.

Membrane integrity of sperm: Lipid being the main membrane constituents of cells play most important role in providing barrier and also involved in cell response to stimuli like hormone, growth factors and neurotransmitters. Peroxidation of lipids by ROS damages the important parts of spermatozoa and thus causes either cell death or altered characteristics of the sperm cells. The reactive oxygen metabolite (ROM) is oxygen centered free radical and their metabolites. Polyunsaturated fatty acid (PUFA) is present in high proportion in lipid fraction of spermatozoa, which reflects the need for maintaining high membrane fluidity and fusion with the oocytes. The main source of ROS is mitochondrial respiration in fresh semen, however in case of processed semen ROS originate from contaminating lecocytes as well as from spermatozoa with residual cytoplasm. Spermatozoa also produces ROS by their flagellar motion contributes the lipid peroxidation [28]. ROS at low concentration shows positive biological effects and also regulate physiological sperm function such as capacitation and sperm egg fusion although it may cause pathological effects with oxidative stress when the oxide exceeds the scavenging activity of antioxidants [29]. Production of ROS can not be prevented completely; however measures may be taken to minimize them to improve semen profile by incorporating various agents like antioxidants, membrane stabilizer and heavy metal scavengers.

Oxidative stress: The oxidative stress is a medical term for damage to animal cells caused by ROS which include superoxide, singlet oxygen, peroxi-nitrite or hydrogen peroxide free radical. It is defined as an imbalance between pro-oxidant and antioxidant, with more pro-oxidant. In other words, oxidative stress is result of imbalance between ROM productions and neutralizing capacity of antioxidant system. Oxidation is essential to nearly all cells in the body to provide energy for vital function. Approximately 95-98 percent of oxygen reduced to water during aerobic metabolism and remaining fraction converted to oxidative by product, ROS that may bring degenerative changes [9].

Antioxidant fortification: The antioxidants are substance, able to neutralize other oxidizable substrate and thus significantly delay or inhibit the oxidation of the substrate at relatively low concentration.

The maintenance of sperm membrane phospholipids and its susceptibility to per-oxidation (oxidation 
Table-2. Effect of additives on motility of sperm after freezing [20]:

\begin{tabular}{lllll}
\hline Stage & Control & $\begin{array}{l}\text { Vitamin-E }(1 \mathrm{mg} / \mathrm{ml}) \\
\text { Mean } \pm \text { S.E }\end{array}$ & $\begin{array}{l}\text { Vitamin-C }(\mathbf{5 M m} / \mathbf{m l}) \\
\text { Mean } \pm \text { S.E }\end{array}$ & $\begin{array}{l}\text { Vitamin E+C }(\mathbf{m g} / \mathbf{m l}+5 \mathrm{Mm} / \mathbf{m l}) \\
\text { Mean } \pm \text { S.E }\end{array}$ \\
\hline Pre-freez & $76.88 \pm 0.02$ & $81.09 \pm 0.01$ & $78.05 \pm 0.02$ & $79.12 \pm 0.02$ \\
Post-thaw & $43.75^{\mathrm{a}} \pm 0.01$ & $50.69^{\mathrm{b}} \pm 0.02$ & $46.83^{\mathrm{ac}} \pm 0.01$ & $47.14^{\mathrm{c}} \pm 0.02$ \\
\%lmprovement over control & - & 15.86 & 7.04 & 7.74 \\
\hline
\end{tabular}

* Means bearing different superscript within same row differ significantly $\left({ }^{\mathrm{abc}} P<0.05\right)$.

by peroxide) depends on adequate antioxidant status, which are responsible for reduction in the risk associated with sperm damage during storage. If there is deficiency of these fractions spermatozoa may get damaged and motility and fertilizing ability diminishes.

Naturally antioxidants are present in seminal plasma, protecting the spermatozoa against lipid peroxidation. Antioxidants are classified as exogenous (natural or synthetic) or endogenous compound, both responsible for removal of free radical, scavenging ROS, inhibiting ROS synthesis and binding metal ions required for catalysis of ROS generation [30]. Natural antioxidant system divided into two groups enzymatic and non enzymatic. Enzymatic antioxidants made up of limited number of proteins like catalase, glutathione peroxidase SOD (superoxide dismutase). Non enzymatic antioxidant classified into direct acting (lipoic acid, poly phenol and carotenoid) and indirect acting antioxidant, which binds to redox metal to prevent free radical generation (Chelating agent). An integrated antioxidant system is provided to the bovine seminal plasma by association of natural antioxidants (vitamin E, Ascorbic acid and glutathione) and antioxidant enzymes (superoxide dismutase, glutathione peroxidase). This system gives the semen protection from free radicals as well as from toxic products of their metabolism. The delicate balance between free radical production and antioxidant defense is an important determinant of grade of semen with respect to fertilizing ability. During period of semen processing like filtration and storage the level of stress and ROS production increases. This will cause enhanced oxidative damage by overwhelming the normal scavenging mechanism of oxygen species by antioxidants in the seminal plasma. Therefore additional antioxidant competence is desired by the sperms. During the process of cryopreservation, irreparable damage can be prevented as well as keeping quality of the cells can be enhanced by fortification of extender with antioxidants.

Antioxidant defense mechanism: The antioxidants provide protection at three levels, 1. Prevention: Prevent initiation of chain reaction, 2. Interception: breaking of chain propagation reaction by formation of non radical end product and 3. Repair [31].

Vitamin $\mathbf{E}$ as antioxidants: Term vitamin $\mathrm{E}$ is generic used for compounds sharing the tocopherol and tocotrienol structures, which are lipid soluble in nature. Vitamin E appears to be the first line of defense against peroxidation and is important for maintaining low tissue concentration of peroxide, which on accumu- lation severely damage the cell and tissue. It is a very efficient scavenger of free radical. Vitamin E localized in cell membrane, therefore it can not protect the cytosol from free radicals, its counterpart "selenium" present in cytosol is responsible for protection in cytosol. Vitamin E increases intracellular ATP and decreases cell permeability and enzyme inactivation $[32,33]$. Vitamin $\mathrm{E}$ was superior over vitamin $\mathrm{C}$ and vitamin $\mathrm{E}+\mathrm{C}$ blend [23]. Vitamin $\mathrm{E}(4.5 \mathrm{mM})$ and Vitamin C $(9 \mathrm{mM})$ was superior over glutathione (7 $\mathrm{mM}$ ) with respect to post-thaw motility [34]. However in buffalo á-tocopherol addition in skim milk based extender did not improve sperm profile significantly [35].

Mechanism of action of Vitamin E: Vitamin E prevents cell damage by binding to the free radical and neutralizing its unpaired electron mediated by an 'tocopheryl-quinone' formation.

Vitamin C as antioxidants: Vitamin $\mathrm{C}$ required for growth and repair of all body tissues and formation of collagen. It protects sperm cell from free radical damage. Antioxidant efficacy of vitamin $\mathrm{C}$ was superior over caffeine and chlorquine in diluter. Fortification of ascorbic acid $(0.02 \%)$ or cholorquine diphosphate $(10 \mathrm{M})$ to extender improves the semen quality and fertility of buffalo bull semen and vitamin $\mathrm{C}$ was slightly superior over Chlorquine diphosphate [36].

Glutathione: Freezing of semen followed by thawing causes a significant reduction in glutathione content in bull sperm. Exogenous glutathione in extender at the dose rate of $2 \mathrm{mM}$ improves post-thaw quality of buffalo bull spermatozoa [37].

Cysteine fortification: Semen extender containing Lcysteine $(1.0 \mathrm{Mm})$ improves the catalase activity [38, 39] plasma membrane integrity [40] and freezability of spermatozoa $[41,42]$.

Pentoxifylline as antioxidants: Split semen sample was used to compare BHA (Butylated Hydroxyl Anisole), BHT (Butylated Hydroxyl Touline) @ 1.5 Mm, Pentoxifylline (PTX) @1.5 mM, Theophylline (TPY) and Theobromine (TBR) with significant improvement in pentoxifylline fortified fraction [43].

n-Propyl gallate as antioxidants: It was superior over vitamin $\mathrm{E}$ and vitamin $\mathrm{C}$ as it has both antioxidant and antimicrobial activity simultaneously.

Coenzyme Q10 and a-lipoic acid: The Coenzyme Q10 and á-lipoic acid are antioxidants that play a role in 
ATP production and break down of free radical which ultimately improves the sperm profile $[44,45]$.

\section{Conclusion}

Washing, sedimentation, swim up and filtration of semen can effectively improve sperm motility, viability, membrane integrity and acrosomal intactness both pre-freez and post-thaw stage of semen preservation. Although it requires interventions and additional sophisticated preparatory stages in standard protocol of cryopreservation of semen, it might be recommended for routine AI work to improve sperm viability after thawing. The washing, sedimentation and filtration can be used for sperm preparation in IVF laboratories by using zona free oocyte preparation test or swim up test for motile sperm separation. Filtration technique is proved efficient and antioxidant fortification is also equally important as far as improving preservation quality of semen is concern, moreover need of hour is, to use it as ready to use package i.e., sperm selection procedure plus antioxidant fortification commercially so that it is constantly used for low grade ejaculates of elite bulls, immediately at large scale.

\section{References}

1. $\quad$ Flipse, R. J., Thacker, D. L. and Almquist, J. O. (1952) Effect of feeding large amount of grass silage to dairy bulls on feed utilization, body measurement and semen quality. J. Dairy Sci., 35: 949.

2. Shannon, P. and Curson, B. (1982) Kinetics of the aromatic L-amino acid oxidase from dead bovine spermatozoa and the effect of catalase on fertility of diluted bovine semen stored at $5^{\circ} \mathrm{C}$ and ambient temperatures. Journal of Reproduction and Fertility., 64: 463-467.

3. Chauhan, I. S., Gupta, A. K., Khate, K., Chauhan, A., Rao, T. K. S., Pathak, S., Hazra, R. and Singh, M. (2010) Genetic and non genetic factors affecting semen production traits in Karan Fries crossbred bulls. Trop Anim Health Prod., DOI 10.1007/s11250-010-9641-z.

4. Ahmad, Z., Anzar, M., Shahab, M., Ahmad, N. and Andrabi, S. M. H. (2003) Sephadex and sephadex ion-exchange filtration improves the quality and freezability of low grade buffalo semen ejaculates. Therogenology., 59: 1189-1202.

5. Anzar, M. and Graham, E. F. (1996) Role of sperm motility and acrosome integrity in the filtration of bovine semen. Theriogenology., 45: 513-520.

6. Rao, T. K. S., Mohanty, T. K., Gupta, A. K., Chauhan, I. S., Singh, M. and Singh, R. R. (2012) Assessment of the efficacy of filtration of low grade ejaculates using different columns on preservability and seminal characteristics of cross bred bull semen. Indian Vet. J., 89 (11): 44-45.

7. Kumaresan, A., Ansari, M. R., Garg, A. and Kataria, M., (2006) Effect of oviductal protein on sperm functions and lipid peroxidation levels during cryopreservation in buffaloes. Anim. Reprod. Sci., 93: 264-257.

8. Andrabi, S. M. H. (2009) Factors affecting the quality of cryopreserved buffalo (Bubalus bubalis) bull spermatozoa. Reproduction in Domestic Animals, 44: 552-569.

9. Garg, A., Kumaresan, A. and Ansari, M. R. (2008) Effect of hydrogen peroxide on fresh and cryopreserved buffalo sperm function during incubation at $37^{\circ} \mathrm{C}$ in-vitro. Reproduction in Domestic Animals, 10: 1439-1445.

10. Andrabi, S. M. H., Ansari, M. S., Ullah, N. and Afzal, M., (2008) Effect of non enzymatic antioxidants in extender on post-thaw quality of buffalo (Bubalus bubalis) bull spermatozoa. Pakistan Vet. J., 28: 159-162.
11. Nair, S. J., Brar, A. S., Ahuja, C. S., Sangha, S. P. and Chaudhary, K. C. (2006) Acomparative study on lipid peroxidation, activities of antioxidant enzymes and viability of cattle and buffalo bull spermatozoa during storage at refrigeration temperature. Anim. Reprod. Sci., 96:21-29.

12. Goyal, R. L., Tuli, R. K. Georgie, G. C. and Chand, D. (1996) Comparison of quality and freezability of water buffalo semen after washing or sephadex filtration. Theriogenology, 46: 679-686.

13. Mustafa, G., Anzar, M. and Arslan, M. (1998) Separation of motile spermatozoa from frozen-thawed buffalo semen: swim-up vs filtration procedure. Theriogenology., 50: 205-211.

14. Chandrahasan, C., Pattabiraman, S. R. and Venkataswami, V. (1986) Studies on the effect of Glass wool column filtration on the quality of semen of cross bred bulls. Indian Vet. J., 63: 913-918.

15. Vyas, S., Dhami, A. J., Mohan, G. and Sahni, K. L. (1991) Effect of sephadex and glass- wool column filtration on the quality and storage (at $5^{\circ} \mathrm{C}$ ) of crossbred bull semen. Indian Journal of Animal Science., 61 (7): 702-704.

16. Lee, H., Kim, S., Ji, D. and Kim, Y. (2009) A comparative study of sephadex, glass wool and percoll separation techniques on sperm quality and IVF results for cryopreserved bovine semen. J. Vet. Sci., 10 (3): 249-255.

17. Arzondo, M. M., Caballero, J. N., Marin-Briggiler, C. L., Davit, G., Cetica, P. D. and Vezquez-Levin, M. H. (2012) Glass wool filtration of bull cryopreserved semen: a rapid and effective method to obtain a high percentage of functional sperm. Theriogenology., 78 (1):201-9.

18. Piperelis, S. G., Vafiadis, D., Boscos , C. M., Brozos, C., Kiossis, E. and Alexopoulos, C. (2008) Efficiency assessment of swift method to enhance substandard viability ram ejaculates. Reproduction in Domestic Animals., 43 (1): 111-6.

19. Scholkamy, T. H., Mahmoud, Karima-Gh. M., El Zohery, F. A. and Ziada, Maha S. (2009) Evaluation of sephadex filtration for freezability and in vitro fertilizing ability of buffalo semen. Global Veterinaria., 3 (2): 144-150.

20. Januskauskas, A., Lukoseviciute, K., Nagy, S., Johannisson, A. and Rodriguez-Martinez, H. (2005) A ssessment of the efficacy of sephadex G-15 filtration of bovine spermatozoa for cryopreservation. Theriogenology., 63: 160-178.

21. Rana, C. M., Dhami, A. J. and Kavani, F. S. (2004) Post-thaw filtration of bovine semen through sephadex gel column: effect on the quality and HOS resistance of spermatozoa. Indian J. Dairy Sci., 57 (2): 96-103.

22. Bhakat, M. (2007) Studies on low grade ejaculates for augmenting semen quality and preservability in dairy bulls. Ph. D. Thesis, NDRI Deemed University, Karnal, Haryana.

23. Rao, T. K. S. (2009) Effect of management and processing intervention on preservability of sub-fertile crossbred bull semen. Ph. D. Thesis, NDRI Deemed University, Karnal, Haryana.

24. Grunewalde, S., Miska, W., Miska, G., Rasch, M., Reinhardt, M., Glander, H. J. and Paasch, U. (2007) Molecular glass wool filtration as a new tool for sperm preparation. Hum Reprod., 22 (5): 1405-1412.

25. Bussalleu, E., Pinart, E., Rivera, M. M., Briz, M., Sancho, S., Yeste, M., Casas, I., Fabrega, A., Rigau, T., Rodriguez-Gil, J. E. and Bonet, S. (2009) Effect of matrix filtration of low quality boar semen dosage on sperm quality. Journal of Reproduction in Domestic Animals., 44 (3): 499-503.

26. Ramio-Lluch, L., Balasch, S., Bonet, S., Briz, M., Pinart, M. and Rodriguez-Gil, J. E. (2009) Effects of filtration through sephadex column improve overall quality parameters and "in vivo" fertility of sub-fertile refrigerated boar-semen. Anim Reprod. Sci., 115 (1-4): 189-200.

27. Parmegiani, L., Cognigni, G. E., Ciampaglia, W., Pocognoli, P., Marchi, F. and Filicori, M. (2010) Efficiency of hyaluronic acid (HA) sperm selection. J Assist Reprod Genet., 27 (1):13-6.

28. Munne-Bosc, S. (2005) The role of alpha-tocopherol in plant stress tolerance. (Special issue: Vitamin E in plants, man and 
animals). J. Plant Physiol., 162(7):743-748.

29. Sikka, S. C., Rajasekaran, M., Hellstrom, W.J.G. (1995) Role of oxidative stress and antioxidants in male infertility. $J$. Androl., 16(6):464-468.

30. Uttara, B., Singh, A. V., Zamboni, P. and Mahajan, R. T. (2009) Oxidative stress and neurodegenerative diseases. A review of upstream and downstream antioxidant therapeutic options. Current Neuropharmacol., 7 (1): 65-74.

31. Sies,H. (1993) Stratgies of antioxidant defense. Eur. J. Biochem., 215:213-219.

32. Breininger, E., Beorlegui,B. Cristian, M. and Beconi, T. (2005) Alpha-tocopherol improves biochemical and dynamic parameters in cryopreserved boar semen. Theriogenology., 63: 2126-2135.

33. Almeida, J. and Ball, A. (2005) Effect of á-tocopherol and tocopherol succinate on lipid peroxidation in equine spermatozoa. Anim. Reprod. Sci., 87: 321-327.

34. Sonia, S., Jindal, S. K., Ramachandran, N., Yadav, S. and Priyadarshni, R. (2012) Standardization of Antioxidant fortification in frozen buck semen. Indian Journal of Small Ruminants., 18 (1): 47-51.

35. Akhter, S., Rakha, B. A., Ansari, M. S., Andrabi, S. M. H. and Ullah, N. (2011) Storage of Nili-Ravi Buffalo (Bubalus bubalis) semen in skim milk extender supplemented with Ascorbic acid and á-Tocopherol. Pakistan J. Zool., 43 (2): 273-277.

36. Cheede, G. S., Pangaonkar, G. R. and Singh, J. (2009) Effect of ascorbic acid and chlorquine diphosphate on the quality and fertility of buffalo semen. Indian Journal of Animal Science., 79 (9): 858-860.

37. Ansari, M. S., Rakha, B. A., Ullah, N., Andrabi, S. M. H., Iqbal, S., Khalid, M. and Akhter, S. (2010) Effect of exogenous glutathione in extender on freezability of Nilirabi buffalo (Bubalus bubalis) bull spermatozoa. Animal
Science Paper and Reports., 28 (3):235-244.

38. Bucak, M. N., Atessahin, A. and Yuce, A., (2008) Effect of anti-oxidants and oxidative stress parameters on ram semen after the freez-thawing process. Small Rum. Res., 75:128-134.

39. Ozkan, S. S., Bucak, M. N., Tuncer, P. B., Ulutas, P. A. and Bilgen, A. (2008) The influence of cysteine and taurine on microscopic-oxidative stress parameters and fertilizing ability of bull semen following cryopreservation. Cryobiology., 58: 134-138.

40. Atessahin, A., Bucak, M. N., Tuncer, P. B. and Kizil, M., (2008) Effect of antioxidant additives on microscopic and oxidative parameters of Angora goat semen following the freez-thawing process. Small Rum. Res., 77: 38-44.

41. El-Sheshtawy, R. I., El-Sisy, G. A. and El-Nattat, WW. S. (2008) Use of selected amino acids to improve buffalo bull semen cryopreservation. Global Veterinaria., 2: 146-150.

42. Ansari, M. S., Rakha, B. A., Ullah, N., Andrabi, S. M. H., Khalid, M. and Akhter, S. (2011) Effect of 1-cysteine in triscitric egg yolk extender on post-thaw quality of nili-ravi buffalo (Bubalus bubalis) bull spermatozoa. Pakistan $J$. Zool., 43 (1):41-47.

43. Pankaj, P. K., Raina, V. S., Roy, B., Mohanty, T. K. and Mishra, A. (2009) Effect of antioxidant preservative on cold protection ability of low grade riverine buffalo (Bubalus bubalis) bull spermatozoa. Asian-Australian Journal of Animal Science., 22 (5):310.

44. Ibrahim, S. F., Osman, K., Das, S., Othman, A. M., Majid, N. A. and Rahman, M. P. (2008) (2008) A study of antioxidant effect of alpha-lipoic acids on sperm quality. Clinics., 63 (4): 545-550.

45. Ibrahim, S. F., Jaffar, F. H. F., Osman, K., Mohamed, S. F. S., Nang, C. F., Ismail, N. H. and Ismail, M. I. (2011) Bull spermatozoa motility: optimization of coenzyme Q10 and alpha-lipoic acid concentration. IIOABJ., 2 (5): 8-13.

$* * * * * * * *$ 